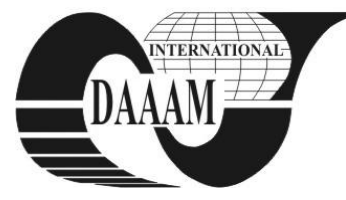

Annals of DAAAM for 2011 \& Proceedings of the 22nd International DAAAM Symposium, Volume 22, No. 1, ISSN 1726-9679 ISBN 978-3-901509-83-4, Editor B. Katalinic, Published by DAAAM International, Vienna, Austria, EU, 2011 Make Harmony between Technology and Nature, and Your Mind will Fly Free as a Bird

\title{
MEASUREMENT OF VERY SMALL ELECTRICAL CAPACITY CHANGES USING BRIDGE METHOD
}

\author{
NAVRATIL, M[ilan] \& KRESALEK, V[ojtech]
}

\begin{abstract}
The main focus of this paper is the practical application of the method for measuring very small changes in capacity at low frequencies. The paper analyzes complete engineering approach to the work of compilation of a workplace, creating a user program, through the optimization of the final engagement of the method for evaluating the results. Key words: measurement, capacity, very little change, bridge
\end{abstract}

\section{INTRODUCTION}

Measurement of very small capacities of organic particles is in practice very difficult and often costly because of the needs of highly sophisticated measuring instruments (Witte, 1993). There is also a need to have very clean and stable environment with minimal noise, vibration, with the requirement for minimum EMI (electromagnetic interference) and high EMS (electromagnetic susceptibility) (Regtiene et al., 2004). In this work we focused on measuring very small capacities of inorganic objects (eg metal plates, coins). With a little deeper reflection it is evident that electrical capacitance and inductance are the subject of two properties that are inherently very difficult to be separated. Even an ordinary conductor has a certain capacity, which indicates the ability of wires to collect electrical charge and inductance (determined by magnetic properties of wires).

We often encountered (especially in heavy current electrical engineering) with the need to compensate for the electrical inductance of electrical capacity and vice versa. This is because setting a state of equilibrium in the system, which in practice has resulted in setting the optimum power factor $(\cos \varphi)$. Again we are at a certain mutual and inseparable scope of these two variables.

In this work we dealt with bridge classical methods, which are in essence very simple (Ferguson, 1933). We use highprecision bridge - LCR meter, which, together with three servo motors controlling the feed to the sensing area of the measuring tip and PC constitute a measuring station. The actuators are controlled displacement of the measuring tip in three axes (x, y, z) and, depending on the shift in the axis will be the LCR meter to measure very small changes in capacitance or inductance $\mathrm{L}$ (deformations of springs).

\section{USED INSTRUMENTS}

Precision LCR meter HP 4284A was used. This instrument provides solution for component and material measurement. It can be used to improve component quality by providing an accurate, high throughput test solution. The wide $20 \mathrm{~Hz}$ to $1 \mathrm{MHz}$ test frequency range and superior test signal performance allow testing components to the most commonly used test standards, such as IEC/MIL standards, and under conditions that simulate the intended application.

\subsection{LCR meter HP 4284A}

\begin{tabular}{|c|c|}
\hline Accuracy & $0.05 \%$ \\
\hline Capacitance Range & $0.00001 \mathrm{pF}-9.99999 \mathrm{~F}$ \\
\hline Current Range & $50 \mathrm{uA}-20 \mathrm{mArms}$ \\
\hline Frequency Range & $20 \mathrm{~Hz}-1 \mathrm{MHz}$ \\
\hline Impedance Range & $0.01 \mathrm{M} \Omega-99.9999 \mathrm{M} \Omega$ \\
\hline Voltage Range & $5 \mathrm{mV}-2 \mathrm{Vrms}$ \\
\hline
\end{tabular}

Tab. 1. Some of the properties of LCR meter HP 4284A

\subsection{Servomotor C-862 Mercury II}

The C-862 Mercury II is the instrument for motion control applications where a precision positioner is to be controlled by a PC or PLC. It features an integrated amplifier and additional TTL I/O capability for flexible automation

In our case, the servo motor is controlled by a set of programmed macroinstructions from PC. Programming environment VEE Pro 9.2 allows us to control the movement of the scanned area towards to measuring tip, speed of movement, the direction of movement (Angus and Hulbert, 2005). In Fig. 1 servo C-862 Mercury II is shown in comparison with the overall view of its size due to the coins.

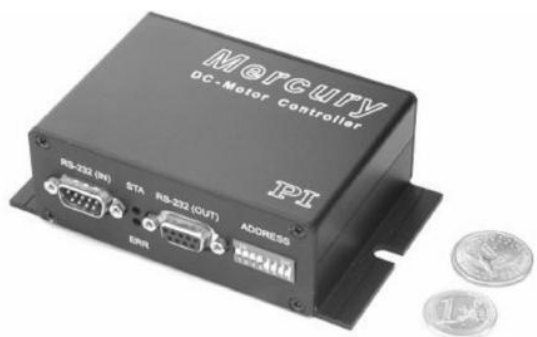

Fig. 1. C-862 Mercury II

Whole block scheme can be seen in Fig. 2

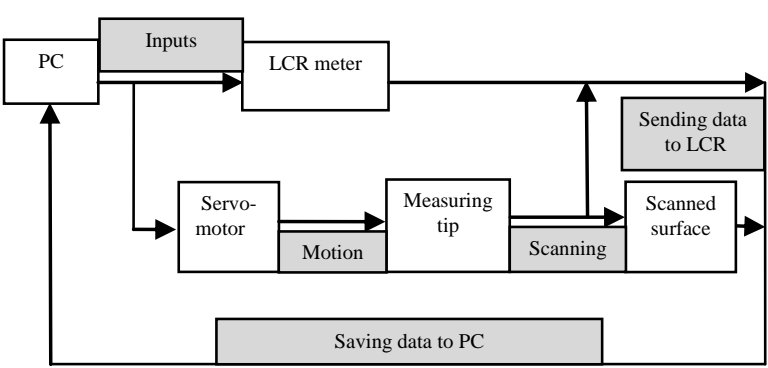

Fig. 2. Block scheme of the measuring system

Inputs - input parameters to instrument (velocity, direction, step, axes).

Motion - servomotor according to input parameters moves the scanned area in given axis (x,y or $\mathrm{z})$.

Scanning - measuring tip connected to static arm measures change in capacity.

Sending data to $L C R$ - changes detected by tip are sent to LCR meter. 


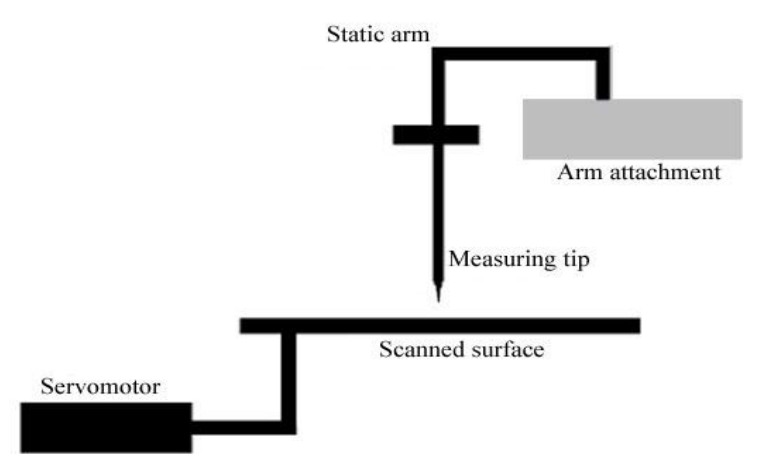

Fig. 3. Electromechanic scheme of the measurement system

Saving data on PC - measured data from LCR meter are stored on PC.

The electromechanic scheme is shown in Fig. 3.The measuring tip is mounted on static arm which is also fastened to the heavy marble slab (due to minimization vibration). The measuring tip itself is static due to moving surface. Appearance of the user application which allows full control of measuring system can be seen in Fig. 4.

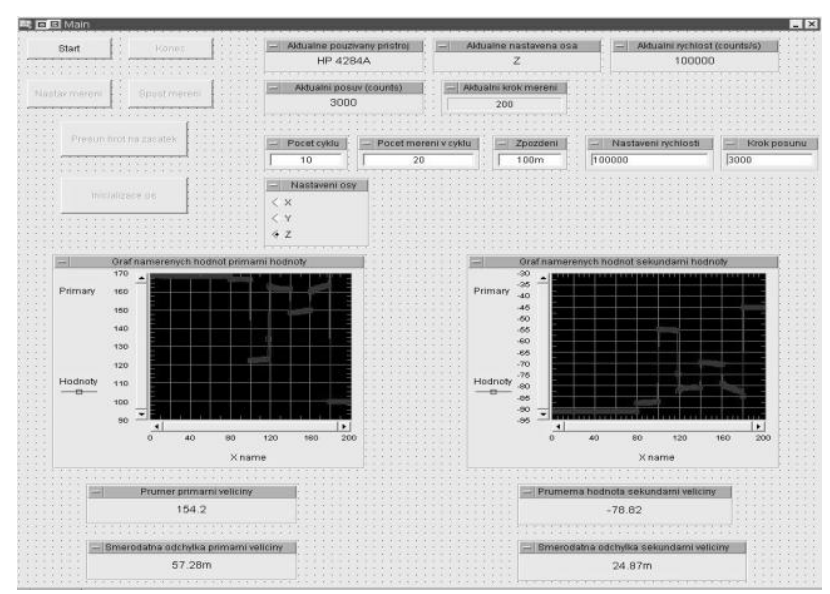

Fig. 4. Control panel of user application in Agilent Vee Pro

\section{RESULTS}

Dependences of electrical capacity on distance at different frequencies are shown in Fig. 5 and Fig. 6. Parameters of measurement are as follows: $\mathrm{d} \quad$ (step) $=18 \mu \mathrm{m} \quad$ and velocity $=100000$ Counts/s (the same for both dependencies), frequencies $=1 \mathrm{MHz}$ and $100 \mathrm{kHz}$. The minimal possible change of electrical capacity $\Delta \mathrm{Cmin}[\mathrm{F}]$ can be determined through derived function of regression curve according measured data - polynomial of degree of three in our case.

Very little capacity changes dependent on motion at $1 \mathrm{MHz}$

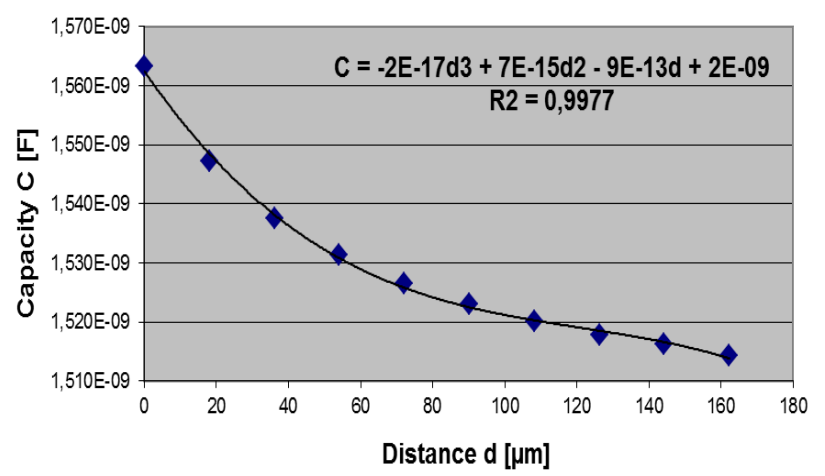

Fig. 5. Electrical capacity measurement at $1 \mathrm{MHz}$

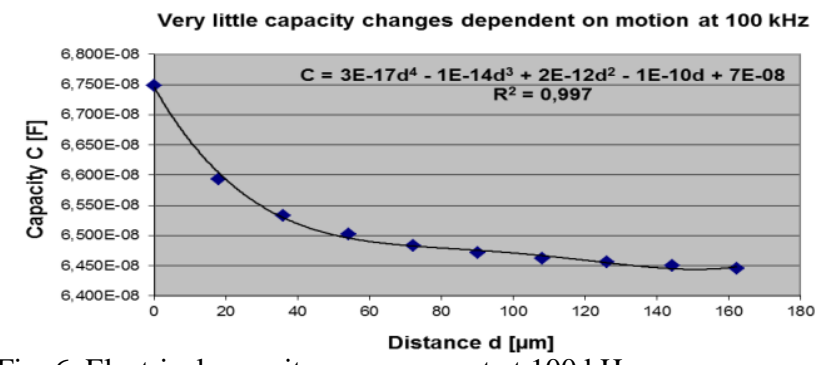

Fig. 6. Electrical capacity measurement at $100 \mathrm{kHz}$

Polynomial function can be expressed like equation (1). Applying derivative according variable $\mathrm{C}$, we can progressively obtain relations (2) and (3). After final modification and insertion of known values, equation (4) is determined and minimal electrical capacity can be calculated for individual regression coefficients.

$$
\begin{gathered}
C=-a_{3} d^{3}+a_{2} d^{2}-a_{1} d+b \\
d C=-a_{3} d d^{3}+a_{2} d d^{2}-a_{1} d d+b \\
\frac{d C}{C}=\frac{-a_{3} d d^{3}+a_{2} d d^{2}-a_{1} d d+b}{-a_{3} d^{3}+a_{2} d^{2}-a_{1} d+b} \\
\Delta C_{\min }=\frac{-a_{3} d^{2}+a_{2} d-a_{1}}{-a_{3} d+a_{2}-a_{1}+\frac{b}{d}}
\end{gathered}
$$

\section{CONCLUSION}

Experimental verification of bridge methods for measuring very small changes in electrical capacity and the gradual optimization showed that the smallest possible changes of electrical capacity $\Delta \mathrm{Cmin}$ we are able to achieve at a frequency of $1 \mathrm{MHz}$, which is the maximal frequency at which the LCR meter can measure. We carried out two types of measurements, - the first one when the surface was moved away from the tip and the second one when the surface approached towards the tip. The best results we achieved at a frequency of $1 \mathrm{MHz}$. When approaching towards the tip it was $\Delta \mathrm{Cmin}=8 \mathrm{nF}$, when moving away it was $\Delta \mathrm{Cmin}=5 \mathrm{nF}$. At a lower frequency at $100 \mathrm{kHz}$ we achieved minimal changes $\Delta \mathrm{Cmin}=26 \mathrm{nF}$ for both directions.

\section{ACKNOWLEDGEMENT}

The work was supported by the Ministry of Education, Youth and Sports of the Czech Republic under the Research Plan No. MSM 7088352102 and by the European Regional Development Fund under the project CEBIA-Tech No. CZ.1.05/2.1.00/03.0089.

\section{REFERENCES}

Angus R. B. \& Hulbert T. E. (2005), VEE Pro: Practical Graphical Programming, Springer-Verlag, ISBN 1-85233870-9, London

Ferguson, J. G. (1933); Classification of Bridge Methods of Measuring Impedances, American Institute of Electrical Engineers, vol.52, no.3, pp.861-867, doi:10.1109/TAIEE.1933.5056408

Regtien P. P. L.; Heijden F.; Korsten M. J. \& Olthuis W. (2004): Measurement science for engineers, Kogan page science, ISBN 1-903996-58-9, London and Sterling, VA

Witte A. R. (1993): Electronic test instruments: theory and applications. Prentice Hall, ISBN 0-13-253147-X, New Jersey 